\title{
Byssus attachment strength of two mytilids in mono-specific and mixed-species mussel beds
}

\section{Jose MF Babarro1*, Luc Comeau²}

Instituto de Investigaciones Marinas, CSIC, Eduardo Cabello, 636208 Vigo, Pontevedra, España $\quad$ *Email: ibabarro@iim.csic.es Department of Fisheries and Oceans, Gulf Fisheries Centre, Science Branch, P.O. Box 5030, Moncton, NB, E1C 9B6, Canada

\section{Introduction}

There is a growing interest to understand co-existence processes between marine species in the bioinvasion scenario. Xenostrobus securis is a small mussel endemic to the brackish waters of New Zealand and Australia and has been listed among the "100 Worst Invasive Species". The mussel Mytilus galloprovincialis is successfully cultivated in Galician Rías. Mussel byssus secretion and its functional strength when subjected to distinct substrate and salinity values were evaluated as the basis to understand dominance patterns within mixed-species beds.

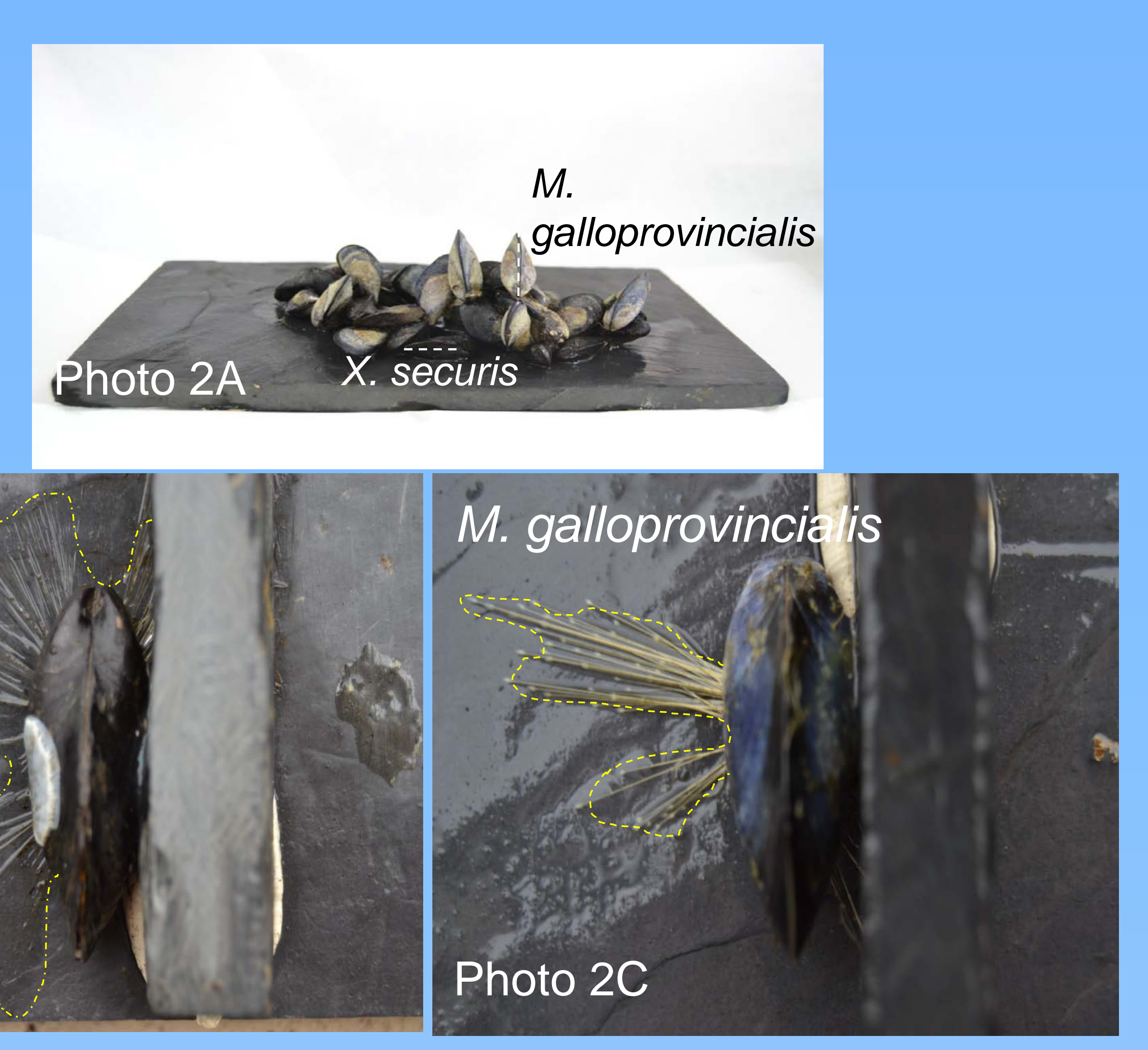

\section{Materials and Methods}

Animals: Mytilus galloprovincialis and Xenostrobus securis were collected from inner Ría de Vigo (NW Spain) with a common size (shell length $35.0 \pm 1.5 \mathrm{~mm}$ ). Fixed density per substrate tile was used ( $n=40$ individuals).

Substrate types and surface analysis: non-treated glass, wood, granite methyl methacrylate, brick, slate and stainless steel were configured in $560 \mathrm{~cm}^{2}$ tiles $(28 \times 20 \mathrm{~cm})$. Bruker Wyko NT1100 Optical Profiler in Vertical Scanning Interferometry (VSI) mode was employed to study the surface topography ( $n=10$ images). A portable Goniometer (PG-2) and distilled water were employed to determine the contact angle (wetting) and the surface free energy.

Flume tank: Filtered seawater at $15^{\circ} \mathrm{C}$ and 35 or 24 psu was used. A diet composed of T-ISO and sediment were pulsed in daily keeping feeding regime in $1.0 \mathrm{mg} \mathrm{l}^{-1}(50 \%$ of organic matter). Mussels were exposed to a variable flow regime $\left(2-15 \mathrm{~cm} \mathrm{~s}^{-1}\right)$ that simulated natural semi-diurnal tides (6-h cycle).

Byssus attachment strength: primary attachment to substrate or on othe mussel's shells were noted after one week of flume exposure e.g. Photo 1 mussel positioning. Detachment force was conducted with mussels immersed in water and skipping neighbours to avoid disturbance when dislodging one individual. A Digital Force Gauge DN431 $( \pm 0.01 \mathrm{~N})$ with peak hold value was used to capture mussel strength, the spring scale pulled perpendicular to the substrate (Photo 1 ).

Byssus coverage: mussels were glued onto fixed vertical posts using 5-min epoxy (Imedio S.A. Madrid, Spain; Photo 2B-C) and suspended $0.6 \mathrm{~cm}$ above the substrate with the posterior end facing upstream. After 1-week exposure, photographs taken from above provided information about the ratio mussel size (shell length versus shell width ellipse) versus byssus coverage area.

\section{Results and Discussion}

\section{Mono-specific beds}

The indigenous Mytilus galloprovincialis consistently showed stronger byssus strength despite lower byssus coverage area (Fig. 1; Photo 2B-C).

The two mussel species responded similarly to substrate factor; mussel strength dropped significantly on methyl methacrylate (Fig. 1). This substrate is widely used as structural adhesive in fiberglass boat construction but only showed difficulties to establish strong attachment, not avoiding byssus secretion. Lower surface free energy values for this substrate ( $\uparrow$ ) would helped to understand such lower strength of attachment (Fig. 2).

The indigenous Mytilus galloprovincialis was more sensitive to salinity drop (24 psu) which would reflect its narrower physiological tolerance (Braby and Somero 2006); the alien Xenostrobus securis behaved as fully euryhaline (Wilson 1968; Babarro and Lassudrie 2011).

\section{Mixed-species beds}

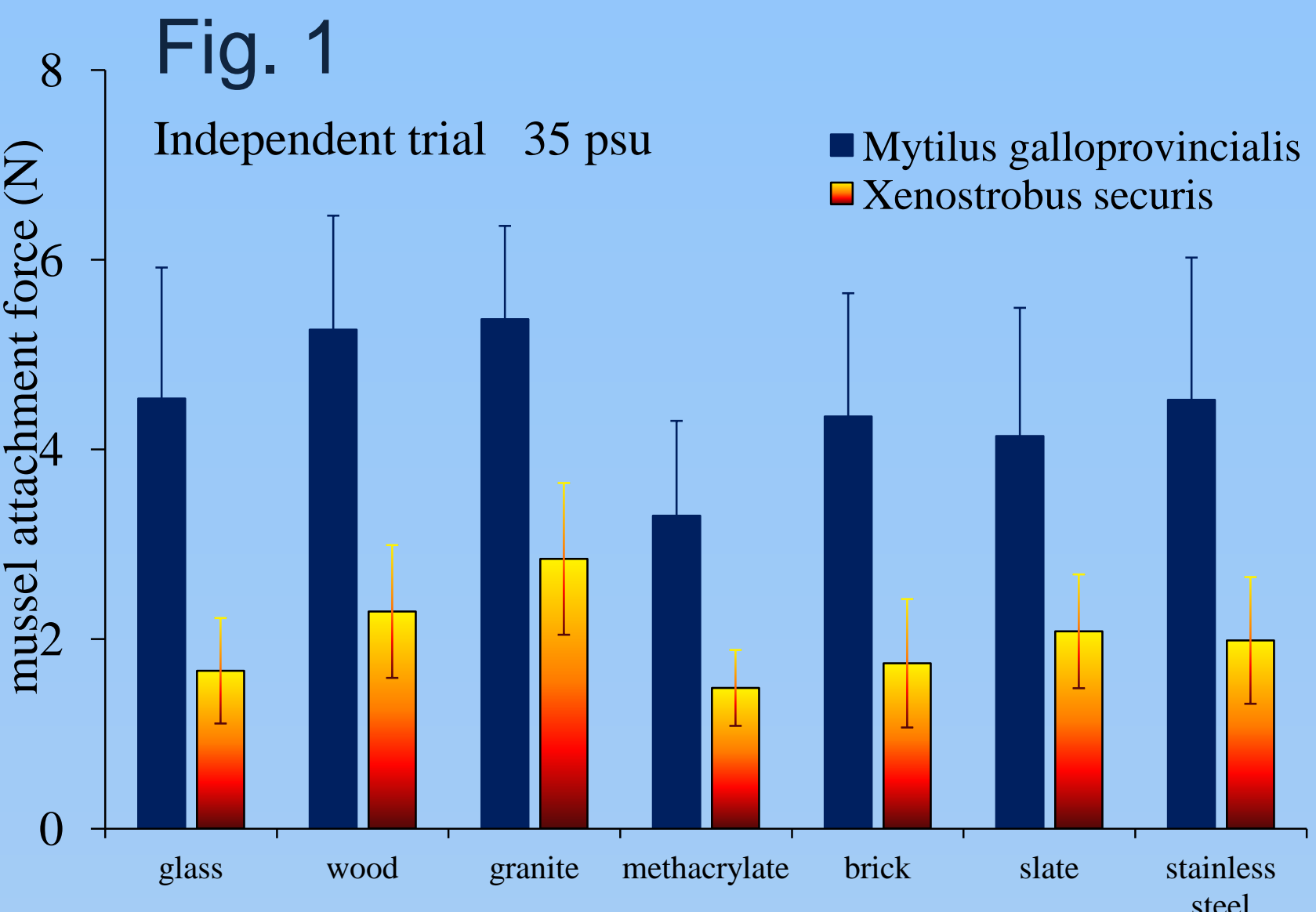

Competitive dynamic on mixed beds highlighted the upwards migratory ability of the alien mussel when space is available; it had been reported before only for the indigenous M. galloprovincialis (Photo 2A; Fig. 3)

The new factor mussel positioning masked the effect of substrate; the use of methacrylate caused the greatest mussel's migration upwards in both species (Fig. 3) and detachment force increase for M. galloprovincialis (Fig. 4).

Both mussel species moved upwards on other's shells but only the alien showed byssus strength increase (Fig. 4); this would reduce greatly the risk of being smothered by M. galloprovincialis and therefore, improving survival rates (Schneider et al. 2005)

\section{Byssus coverage}

Mean byssus coverage ratio was greater for the alien mussel (1.34) as compared to the native mussel (0.30), as a good successful invader in all substrate types (Photo 2B-C)

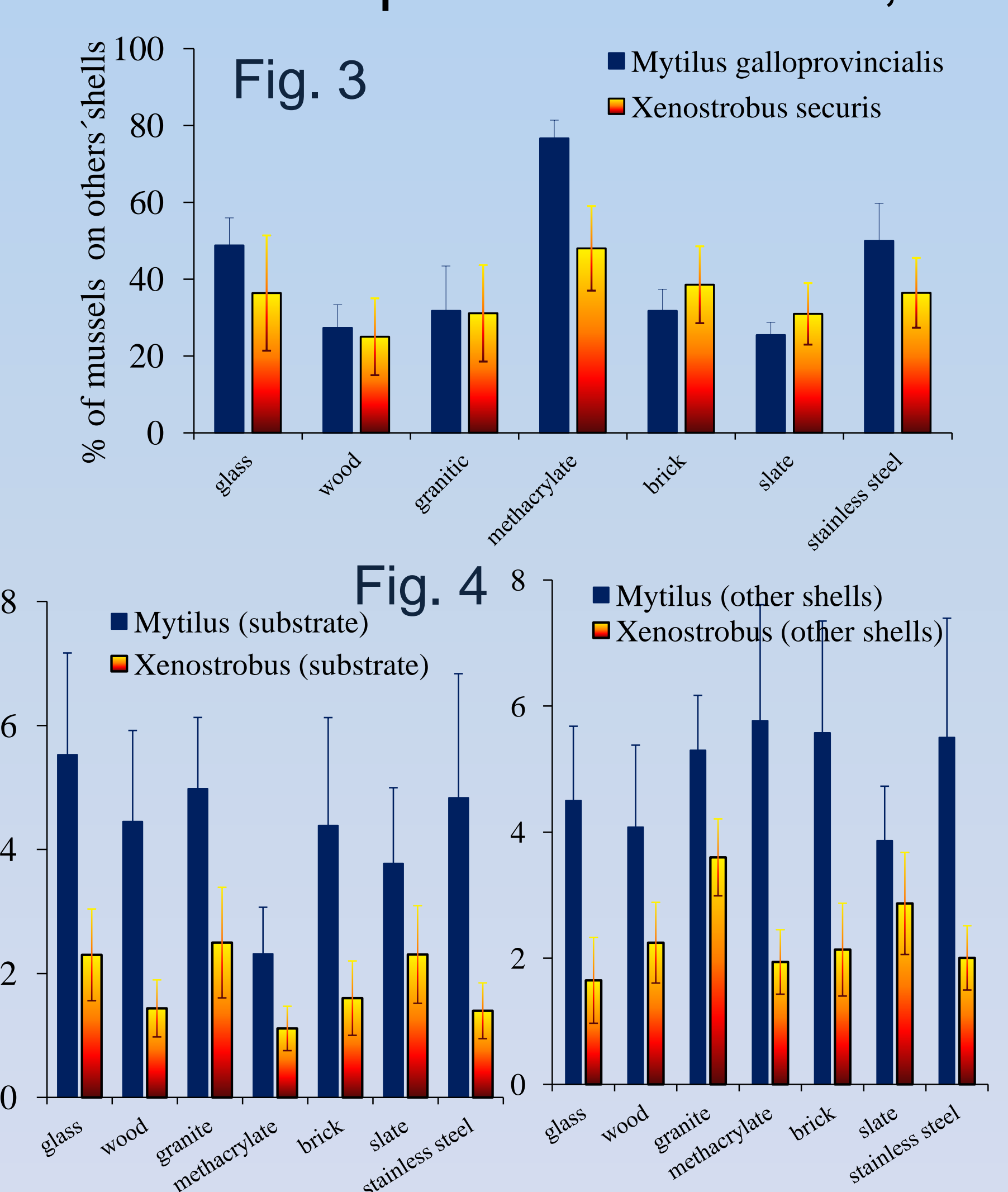

Byssus net established by the alien mussel was also more homogeneous facing substrate and salinity variations in comparison to the much less tolerant indigenous mussel.

\section{Conclusions}

$\square$ Xenostrobus securis adapted to a wide range of substrates and salinities, which may promote its dissemination in estuarine environments

$\smile$ Understanding attachment responses of this alien mussel species is useful for developing control management strategies

$\square$ Substrate type had minor influence on byssus attachment strength of mixed assemblages. Only the alien $X$. securis benefited from environmental heterogeneity despite its consistently lower byssus strength

\section{Acknowledgements}

We thank Elsa Silva Caride for technical assistance. This study was funded by the project AGL2010-16464 (Ministerio de Ciencia e Innovación, Spanish Government). We also thank Dr. Carmen Serra Rodríguez (C.A.C.T.I.) who carried out surface analyses.

\section{References}

Babarro and Lassudrie (2011). Aquat Living Resour 24:303-315 Braby and Somero (2006). J Exp Biol 209:2554-2566

Schneider et al. (2005). Mar Biol 146:333-343

Wilson (1968). J Nat Hist 2:307-328 